Удк 338.43

\author{
N.V. Kozlova, A.M. Petimko
}

\section{AGROMARKETING AS AN INSTRUMENT FOR INCREASING ECONOMIC STABILITY OF ENTERPRISES OF THE AGRICUL- TURE OF RUSSIA}

The article is devoted to the problems of increasing the stability of enterprises in the agricultural sector of the Russian economy. The relevance of using agro-marketing in the current conditions of agroeconomics is emphasized. The place of the agricultural sector in the structure of the Russian economy is shown. The types of enterprises with a certain degree of economic stability, operating in adverse, sometimes destructive conditions of the Russian agro-industrial complex, are presented. The results of the analysis of modern agribusiness with the typification of the causes of a negative trend are presented. The vector orientation, configuration and priorities of the state agrarian policy in the long term are determined. The issue of the national project "Development of the agroindustrial complex" is touched upon. The essence of the implementation of the State Program for the Development of Agriculture from the perspective of the sustainability of today's agricultural sector of the economy is revealed. The rationale for the use of agromarketing tools aimed at increasing the stability of the functioning of agribusiness enterprises, increasing the competitiveness of agricultural products, both in the domestic and foreign markets, is given. The specific features of agromarketing are considered. The main provisions are formulated that reveal the essence, peculiarity, and the prospect of using agromarketing by agribusinesses. The factors are compiled that determine the application efficiency of agromarketing to agricultural enterprises.

Keywords: agribusiness, agricultural enterprises, state program, agroeconomics, agromarketing, agribusiness, KFH (peasant farming), resource conservation, competitiveness, economic sustainability.

\section{Н.В. Козлова', А.М. Петимко ${ }^{2}$ \\ АГРОМАРКЕТИНГ КАК ИНСТРУМЕНТ ПОВЫШЕНИЯ ЭКОНОМИЧЕСКОЙ УСТОЙЧИВОСТИ ПРЕДПРИЯТИЙ АПК РОсСИИ}

Статья посвящена проблемам повышения устойчивости предприятий аграрного сектора экономики России. Подчёркивается актуальность использования агромаркетинга в современных условиях агроэкономики. Приводятся результаты анализа современного АПК. Даётся обоснование применения инструментов агромаркетинга, направленных на повышение устойчивости фрунционирования предприятий агробизнеса, повышение конкурентоспособности продукции агропредприятий, как на внутреннем, так и на внешних рынках. Сформулированы основные положения, раскрывающие сущность, особенность, перспективу применения агромаркетинга агропредприятиями.

Ключевые слова: АПК, агропредприятия, госпрограмма, агроэкономика, агромаркетинг, агробизнес, КФХ (крестьянскофрермерское хозяйство), ресурсосбережение, конкурентоспособность, экономическая устойчивость.

\footnotetext{
${ }^{1}$ Козлова Н.В., доцент кафедры маркетинга, кандидат экономических наук, доцент; ФГБОУ ВО "Белгородский государственный технологический университет им. В.Г. Шухова", г. Белгород

Kozlova N.V., Associate Professor of the Department of Marketing, PhD in Economics, Associate Professor; Federal State Budgetary Educational Establishment of Higher Education "Belgorod State Technological University named after V.G. Shukhov", Belgorod

E-mail: apolo2007@mail.ru

${ }^{2}$ Петимко А.М., доцент кафедры маркетинга, кандидат экономических наук, доцент; ФГБОУ ВО "Белгородский государственный технологический университет им. В.Г. Шухова", г. Белгород

Petimko A.M., Associate Professor of the Department of Marketing, PhD in Economics, Associate Professor; Federal State Budgetary Educational Establishment of Higher Education "Belgorod State Technological University named after V.G. Shukhov", Belgorod

E-mail: ang_pet@mail.ru
} 
Проблема обеспечения населения качественными продовольственными продуктами является одним из доминирующих аспектов национальной безопасности и напрямую зависит от эфффективности развития агропромышленного комплекса (АПК) нашей страны (продовольственная безопасность обеспечивается за счёт развития биотехнологий и импортозамещения по основным продуктам питания, а также путём предотвращения истощения земельных ресурсов и сокращения сельскохозяйственных земель и угодий.)

Решение этой актуальной и по сегодняшний день проблематики требует устойчивого, стабильного развития аграрной отрасли.

Мы придерживаемся мнения, что аграрный комплекс - это:

- "скрепа" России;

- $\quad$ особый ресурс, умелое управление которым способно сделать Россию агроцивилизованной страной;

- мощный актив развития социально-экономической системы страны, будущий драйвер российской экономики.

Нельзя не отметить тот факт, что сегодня российскому АПК присущи такие деструктивные процессы, как:

1) деградирование сельскохозяйственных и лесных угодий. Последние переходят в разряд непродуктивных и, что ещё хуже, неиспользуемых;

2) разрушение природно-ресурсного потенциала (наблюдается снижение содержания элементов питания и гумуса в почвах сельскохозяйственных угодий практически на территории всех регионов страны);

3) критическое состояние экологии российской земли - стремительный рост площади пахотных земель, используемых в качестве "полигонов" для промышленных и бытовых отходов;

4) хаотичное функционирование рынка земли (отсутствие механизма рационализации землепользования, эффрективной системы контроля со стороны государства и ответственности самих землепользователей за эксплуатацию земли);

5) диспаритет цен (цены на продукцию российских аграриев крайне низки, в то время как стоимость топлива, сельскохозяйственного оборудования, запасных частей к ним, кратно выше);

6) рост убыточных, нерентабельных хозяйств агробизнеса, в том числе КФХ (крестьянско-фрермерских хозяйств). Типичными причинами такой отрицательной динамики являются:

Апк - диктат местных монополистов в системе ценообразования на продукцию АПК; предоставление предприятиям агробизнеса кратко- и долгосрочных кредитов под высокие процентные ставки;

- $\quad$ отсутствие преференций для аграриев со стороны правительства и региональных органов власти; ной продукции;

7) существенные потери при сборе, хранении, логистике сельскохозяйствен-

8) отсутствие механизма защиты экологических интересов отечественных товаропроизводителей.

Тормозом АПК было и остаётся техническое отставание и физическая нехватка инфраструктурных мощностей, особенно для экспорта: современных хранилищ плодоовощной продукции, портово-перевалочных комплексов в отдельных регионах, мелиоративных сооружений. Но, по мнению некоторых отраслевых специалистов, есть уверенность, что именно этот сопутствующий агросектору сегмент будет двигателем роста отрасли в среднесрочной перспективе.

В таких не совсем благоприятных условиях макро- и мезосреды АПК эффективно функционировать могут позволить себе не все предприятия агоробизнеса. Вместе с тем, реализуемая в РФ Госпрограмма развития сельского хозяйства и регулирования рынков сельскохозяйственной продукции, сырья и продовольствия на 2013-2020 гг. послужила мощным стимулом для аграриев.

Устойчивыми агропредприятиями стали те, кто получили высокую государственную поддержку в виде преференций - субсидий, льготного кредитования, низких процентных ставок по кредиту, агрострахование и т.п.; мегакомплексы (свиноводческие, птицеводческие, племенные заводы и т.д.), отличающиеся высокой концентрацией в аграр- 
ной отрасли и использованием технологии глубокой переработки; предприятия, оптимизировавшие посреднические услуги и самостоятельно наладившие переработку агросырья, а также организовавшие сбыт продукции через собственную торговую сеть.

По данным аналитической компании INFOLine, которая подготовила очередной рейтинг крупнейших агрокомпаний России по выручке в 2018 г., следует, что совокупный оборот топ-10 участников в исследуемый период увеличился на 4,7 \% - до 645,8 млрд руб. без учёта НДС (Рис. 1).

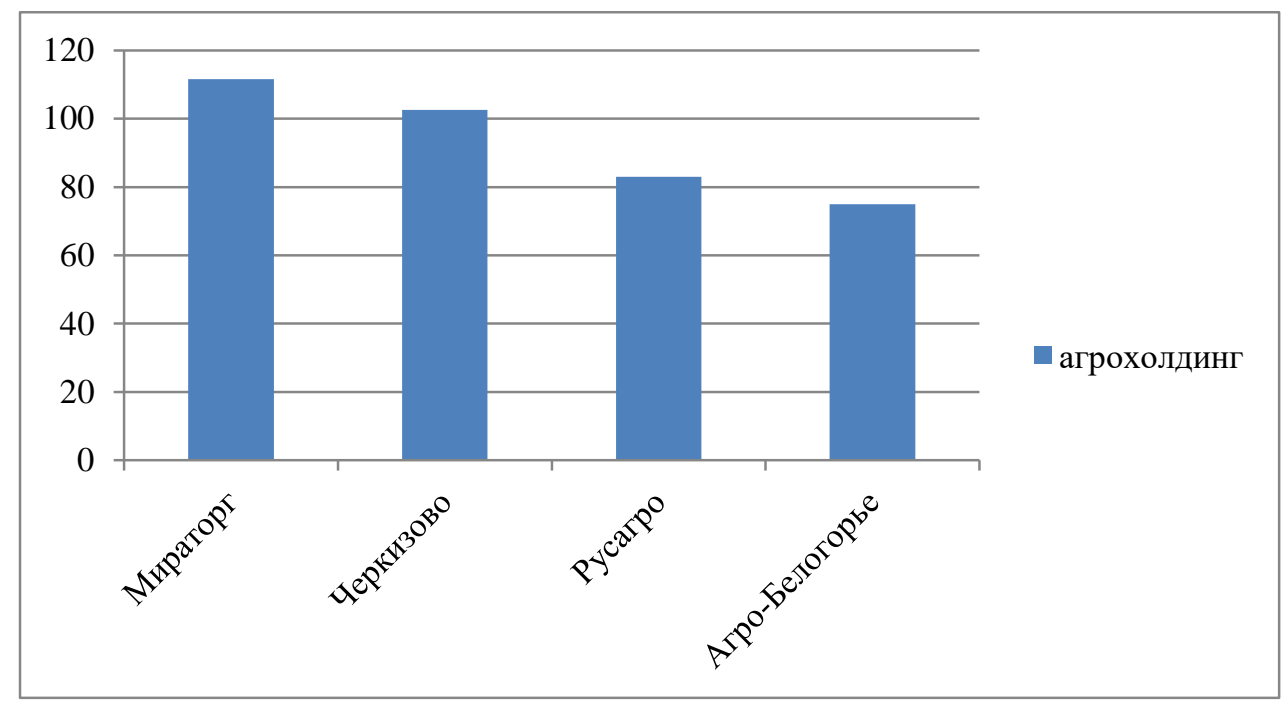

Рис. 1 - Рейтинг крупнейших агрохолдингов России по выручке в 2018 г. (млрд руб.)

Первое место в рейтинге стабильно занимает агропромышленный холдинг "Мираторг", специализирующийся на производстве и поставках мяса на российском рынке.

На втором месте, как в 2017 г., находится группа "Черкизово", один из крупнейших российских производителей мясной продукции и мясных полуфабрикатов. В состав Группы входят 8 птицеводческих и 15 современных свинокомплексов, а также 3 земельных кластера и 6 комбикормовых заводов, 6 мясоперерабатывающих заводов, оснащённых современным оборудованием, во главе с фрлагманом - "Черкизовским мясоперерабатывающим заводом".

Третью позицию сохранила группа компаний "Русагро", крупнейший вертикальный агрохолдинг России. В настоящее время занимает лидирующие позиции в производстве сахара, свиноводстве, растениеводстве и масложировом бизнесе.

Четвёртое место в этом году занимает группа компаний "Агро-Белогорье", в приоритете которой промышленное свиноводство, молочное животноводство, растениеводство и кормопроизводство.

Основные факторы, оказывающие влияние на динамику АПК в целом и агрохолдингов в частности, остаются прежними: мировая конъюнктура, господдержка, реализация экспортного потенциала. Однако в исследовании говорится и о том, что на фоне стагнации внутреннего рынка на выручку компаний будет оказывать влияние продолжающаяся консолидация отрасли. Аналитики INFOLine прогнозируют увеличения на рынке сделок по слиянию и поглощению активов в среднесрочной перспективе.

Мониторинг отраслевой конъюнктуры свидетельствует о поступательном тренде аграрного сектора экономики.

Так, в 2018 г. индекс производства сельхозпродукции составил 107,2 \% по отношению к 2015 г., что выше целевого показателя Госпрограммы. Рентабельность сельхозорганизаций достигла $12,5 \%$, а среднемесячная заработная плата работников в сельском хозяйстве на 26 \% превысила плановое значение. Достигнуты или превышены пороговые значения по таким направлениям, как производство зерна, сахара, растительного масла, мяса и мясопродуктов. 
Динамично стала развиваться торговля продукцией АПК с иностранными государствами. По сравнению с 2017 г. товарооборот с зарубежными странами увеличился почти на $10 \%$.

Наращивание российского экспорта сельхозпродукции и продовольствия - одна из "точек роста" для агробизнеса на ближайшую перспективу.

Динамика развития АПК на период до 2020 г. будет фрормироваться под воздействием разновекторных факторов. С одной стороны, скажутся меры, которые были приняты в последние годы по повышению устойчивости агропромышленного производства, с другой - сохранится сложная макроэкономическая обстановка, усиливающая вероятность проявления рисков для аграрного сектора экономики.

Вместе с тем, перспективы аграрной политики государства приобретают всё более чёткую конфигурацию. Выкристаллизованные 7 приоритетов Госпрограммы затрагивают всю палитру проблем российского АПК:

1. Развитие инфраструктуры агропродовольственного рынка.

2. Модернизацию пищевой и перерабатывающей промышленности.

3. Увеличение объёмов экспорта сельскохозяйственной продукции и продовольствия.

4. Развитие фермерства и малых фрорм хозяйствования с целью формирования сильного класса собственников и предпринимателей на селе.

5. Реализацию комплекса стратегических мер, направленных на снижение рисков неблагоприятных природно-климатических условий в сельском хозяйстве - развитие мелиорации и страхования.

6. Устойчивое развитие сельских территорий, социальной, инженерной и дорожной инфраструктуры.

7. Эффективное развитие науки и образования.

Рис. 2.

Динамика развития АПК и её прогноз в период до 2020 г. представлены нами на

По данным Министерства сельского хозяйства Российской Федерации с 2012 по 2020 гг. производство продукции сельского хозяйства вырастет на 21 \% относительно уровня 2011 г. В том числе производство продукции животноводства - вырастет на $25 \%$; производство продукции растениеводства - на $17 \%$.

Мировой опыт свидетельствует, что экологическая и продовольственная безопасность в значительной мере зависят от действующих механизмов государственного управления в области рационального использования, охраны и восстановления природных ресурсов.

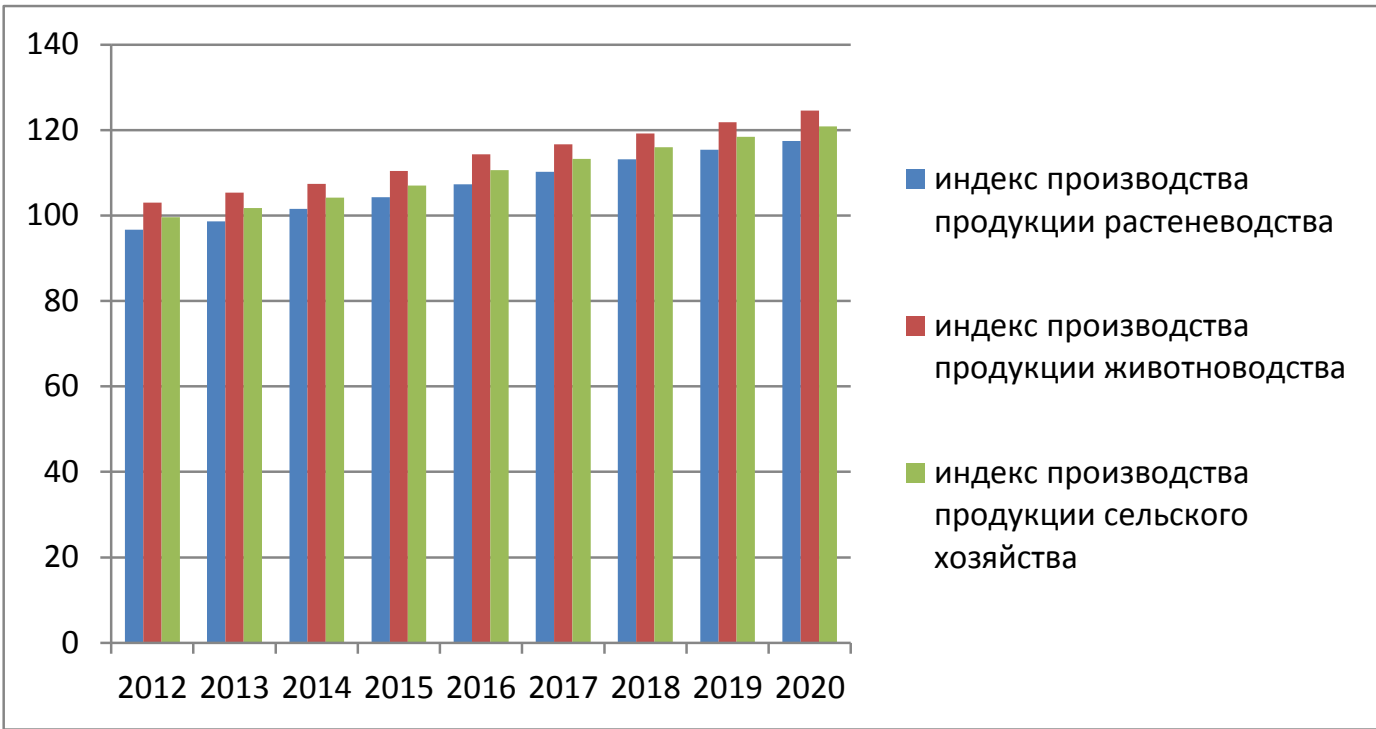

Рис. 2 - Динамика развития АПК в соответствии с новой Государственной программой

Нельзя не обратить внимания на один из приоритетных национальных проектов "Развитие АПК". Начиная с 2008 г. данный проект трансформировался в Государственную 
программу развития сельского хозяйства и регулирования рынков сельскохозяйственной продукции, сырья и продовольствия.

В проектную часть Госпрограммы включены фредеральные проекты "Экспорт продукции агропромышленного комплекса" (таблица) и "Создание системы поддержки фермеров и развитие сельской кооперации", ведомственные проекты "Развитие отраслей агропромышленного комплекса, обеспечивающих ускоренное импортозамещение основных видов сельскохозяйственной продукции, сырья и продовольствия", "Стимулирование инвестиционной деятельности в агропромышленном комплексе", "Техническая модернизация агропромышленного комплекса", "Цифровое сельское хозяйство", а также ведомственная программа "Развитие мелиоративного комплекса России".

Таблица - Финансирование мероприятий феедерального проекта "Экспорт продукции АПК"

\begin{tabular}{|c|c|c|c|}
\hline Наименование мероприятий & На 2019 г. & На 2010 г. & Ha 2021 г. \\
\hline Всего, млрд руб. & 38809,6 & 33809,6 & 66519,0 \\
\hline Льготное кредитование & 17733,9 & 11379,0 & 51097,6 \\
\hline Развитие мелиорации & 2496,0 & 2753,1 & 5810,4 \\
\hline $\begin{array}{l}\text { Компенсация части затрат российскими } \\
\text { организациями на транспортировку } \\
\text { сельхозпродукции и продовольствия }\end{array}$ & 1275,0 & 2332,0 & 3388,0 \\
\hline $\begin{array}{l}\text { Компенсация части прямых затрат на } \\
\text { строительство объектов АПК }\end{array}$ & 0,0 & 4256,0 & 2972,8 \\
\hline Сертификация сельхозпродукции & 0,0 & 400,0 & 448,0 \\
\hline Мероприятия Россельхознадзора & 2084,2 & 2051,0 & 2009,4 \\
\hline $\begin{array}{l}\text { Государственная поддержка организаций в } \\
\text { целях продвижения продукции АПК на внешние } \\
\text { рынки }\end{array}$ & 50,0 & 50,0 & 50,0 \\
\hline $\begin{array}{l}\text { Формирование единой архитектуры } \\
\text { национального странового бренда (стратегия } \\
\text { продвижения продуктовых групп на внешние } \\
\text { рынки с программой их рекламно- } \\
\text { инфрормационного продвижения) }\end{array}$ & 50,0 & 50,0 & 50,0 \\
\hline
\end{tabular}

В целом, выполнение Госпрограммы направлено на обеспечение устойчивости производства по основным видам сельскохозяйственной продукции, развитие экспортной составляющей, повышение инвестиционной привлекательности агробизнеса, улучшение социального кластера села.

Справедливости ради отметим, что достижение целей Госпрограммы возможно лишь при рациональном использовании средств государственной поддержки и эффрективной модели менеджмента.

Не будет преувеличением сказать, что консолидирующей функцией менеджмента и современным адекватным инструментом, способным оптимизировать ограниченные ресурсы, снизить издержки обращения, существенно повысить устойчивость предприятий АПК, является агромаркетинг.

В России агромаркетинг имеет довольно узкую практическую направленность и, по сути, находится в стадии становления.

Являясь самостоятельным направлением современного маркетинга, агромаркетинг нацелен, с одной стороны, на удовлетворение спроса населения в товарах, услугах сельскохозяйственного производства, а с другой - на выстраивание модели партнёрских отношений с элементами мезосреды.

Сегодняшняя аграрная экономика РФ, характеризующаяся большим разнообразием участников (сельские товаропроизводители, обслуживающие АПК компании, предприятия по переработке продукции, оптовые рынки, потребительские кооперативы, банковская сфера и т.д.), определяет технологию агромаркетинга, набор инструментов и действий:

- анализ агромаркетинговой среды;

- комплексную оценку потенциала предприятия, хозяйства и т.п.;

- построение рыночной структуры управления аграрным производством;

- установление устойчивости товаров на рынке сельскохозяйственной продукции и принципов конкурентной борьбы; 
- формирование конкурентоспособной цены;

разработку эффрективной ФОСАС (формирование спроса и активизация сбыта);

формирование стратегии и тактики агромаркетинговой деятельности и т.д.

Комплексное, системное, научно-обоснованное использование технологии агромаркетинга обуславливает выработку эфффективных стратегических решений предприятий сфреры АПК.

Необходимо понимать - генерирование агромаркетинговых идей, закладываемых в концепцию развития устойчивого агробизнеса любой территории, в целом определяется и многоаспектной диагностикой рынка АПК, и выявлением агромаркетинговых проблем, и культурой инфоормационных систем и искусством взаимоотношений в системе потребитель-производитель, и, что самое важное, правовой компонентой и спецификой аграрного хозяйства России.

К специфическим особенностям агромаркетинга нами в частности отнесены:

- тесная связь с биологическими системами,

- устойчивый объём потребления,

- диверсификация производства,

- технологическая зависимость сопряжённых производств,

- большой объём скоропортящейся продукции,

- монополизация переработки,

- концентрация потребителей по территориям.

Эффрективность применения агромаркетинга сельхозиндустрией в практической плоскости зависит от:

1. Глубокой оценки состояния конъюнктуры рынка и потенциала сельскохозяйственного предприятия.

2. Корректно сфрормулированных, верно поставленных стратегических целей и тактических задач агромаркетинга. Важно, чтобы эти цели не диссонировали с целями агробизнеса.

3. Грамотно спланированной дорожной карты реализации маркетинговых мероприятий (оптимальная организация системы маркетинга, бережливая система управления, центры ответственности, сроки исполнения, организация системы контроля и т.д.).

4. Своевременного, оперативного вмешательства в ход реализации дорожной карты мероприятий агромаркетинга, в связи с постоянно меняющейся конъюнктурой.

5. Максимальной творческой отдачи от всего маркетинг-персонала (вне зависимости от его принадлежности к предприятию).

6. Обеспечения объективной, актуальной информацией о маркетинговой среде.

Акцентируем внимание на том, что устойчивое положение на современном агрорынке, способность держать удар со стороны конкурентов возможно не только тогда, когда сельхозпроизводители достаточно уверенно ориентируются на сегодняшние потребности покупателей, этого, увы, недостаточно. Аграриям просто необходимо знать, что будут предпочитать потребители уже завтра. По существу, агробизнес должен овладеть технологией управления маркетинговой информацией. Особенностью последней является то, что она не только объёмна, но ещё и разнопланова и сложна. В этой связи встаёт необходимость разработки особой системы агромаркетинговой инфоормации.

Таким образом, использование агромаркетинга, как мы полагаем, может и должно стать мощным ресурсосберегающим инструментом повышения конкурентоспособности, экономической эфффективности и устойчивости агробизнеса. Мы объясняем это тем, что агромаркетинг, как сложная, но, тем не менее, гибкая оперативная система управления, включающая в себя комплекс рыночных отношений и информационных потоков, охватывает все стадии движения товара, начиная с изучения потребностей клиентурного рынка, и заканчивая организацией послепродажного сервиса, и связывает в единое звено предприятие аграрного сектора с элементами макро- и мезосреды.

\section{Список использованных источников}

1. Указ Президента РФ от 12.05 .2009 г. № 537 "О стратегии национальной безопасности Российской Федерации до 2020 года".

2. Материалы Конгресса Общероссийской общественной организации "Российское общественное объединение экономистов-аграрников". Государственный университет по благоустройству, 14 июня 2018 года / Под общей редакцией академика РАН С.Н. Волкова, эксперта РАН, д.э.н., проф. Ю.А. Цыпкина. - М., ГУЗ, 2008. 
3. Асеев Ю.И. Агробизнес в России: (некоторые вопросы теории и практики): монография / Ю.И. Асеев; М-во сельского хоз-ва РФ, ФГОУ ВПО Ставропольский гос. аграрный ун-т. - Ставрополь: Мир данных, 2007. - 381 с.

4. Данилов А.И. Экономический механизм обеспечения конкурентоспособности предприятий аграрной сферы АПК: монография. - М.: Информ.-внедренческий центр "Маркетинг", 2010. - 96 с.

5. Ильин С.С. Государственное экономическое регулирование аграрной сферы АПК России: история, теория и практика / С.С. Ильин. - М.: Социум, 2009. - 599 с.

6. Клюкач В.А. Маркетинг в агропромышленном комплексе. Учебник / В.А. Клюкач, Д.А. Логинов. - Екатеринбург: Урал, ГСХА, 2009. - 491 с.

7. Комов Н.В., Шарипов С.А. Земельные ресурсы в стратегии устойчивого развития России: монография. - Казань: "Бриг", 2017. - 480 с.

8. Комов Н.В. Управление земельными ресурсами в новой России: монография. - Казань: РИЦ, 2011. - 568 с.

9. Кононова О.Ю., Затолокин Н.М., Мелентьев А.А. Использование земель сельскохозяйственного назначения на современном этапе на территории Белгородской области. Вестник БГТУ им.В.Г. Шухова. - Белгород: РИЦ БГТУ им. В.Г.Шухова, 2017. - 234 (5), 227-232.

10. Мацкуляк И.Д. Аграрная экономика: основные понятия / И.Д. Мацкуляк, В.Н. Боробов, А.Б. Ярлыкапов. Российская акад. гос. службы при Президенте Российской Федерации. - М.: РАГС, 2010. - 420 с.

11. Минаков И.А., Сабетова Л.А., Куликов Н.И. и др.. Экономика сельского хозяйства / Под редакцией И.А. Минакова. - М.: КолосС, 2003. - 328 с.

12. Панкрухин А.П. Маркетинг территорий. Учебное пособие. - М.: РАГС, 2002. $328 \mathrm{c}$.

13. Цыпкин Ю.А., Люкшинов А.Н., Эриашвили Н.Д. Агромаркетинг и консалтинг: Учеб. пособие для вузов / Под редакцией проф. Ю.А. Цыпкина. - М.: ЮНИТИ-ДАНА, 2000. $-637 \mathrm{c}$.

14. Цыпкин Ю.А., Люкшинов А.Н. Менеджмент в АПК. - М.: Мир, 2007. - 264 с.

15. Маркетинг в агропромышленном комплексе. Учебник и практикум для академического бакалавриата / Под редакцией Н.В. Суриковой. - М.: Юрайт, 2019. - 314 с.

16. Управление маркетингом в АПК. Учебник / Под редакцией А.В. Пашатова. М.: РГАУ-МСХА им. К.А. Тимирязева, 2011. - 278 с.

17. ОTP программа "Аграрная политика" от 16 апреля 2018 г. - URL: https://otronline.ru/programmi/segodnya-v-rossi/aleksandr-petrikov-pochemu-81903.html (дата обращения: 3 октября 2019).

18. Развитие сельского хозяйства в России: реалии и перспективы. 2016. - URL: https://www.kp.ru/guide/razvitie-sel-skogo-khozjaistva-v-rossii.html (дата обращения: 1 октября 2019).

19. Итоги госпрограммы развития АПК в 2018 году. 2019. - URL: https://agrovesti.net/news/indst/itogi-gosprogrammy-razvitiya-apk-v-2018-godu.html (дата обращения: 15 сентября 2019).

20. Минсельхоз представил проект обновлённой госпрограммы развития АПК до 2025 года. 2019. - URL: https://milknews.ru/index/selskoe-hozyaystvo/mskh-proekt-razvitiyaapk-2025.html (дата обращения: 23 сентября 2019).

21. "Мираторг" вновь возглавил рейтинг агрохолдингов по выручке. 2019. - URL: https://www.agroinvestor.ru/rating/news/32339-miratorg-vnov-vozglavil-reyting-agrokholdingov/ (дата обращения: 3 сентября 2019).

22. Основные направления государственной политики в сфере АПК на 2019 и последующие годы. 2018. - URL: https://agrovesti.net/lib/industries/osnovnye-napravleniyagosudarstvennoj-politiki-v-sfere-apk-na-2019-i-posleduyushchie-gody.html (дата обращения: 11 сентября 2019). 